\title{
Challenges of Industrial Engineering, Management and ICT
}

\author{
Lucia Knapcikova' $^{1}$ Dragan Peraković ${ }^{2}$
}

Accepted: 9 March 2021 / Published online: 19 March 2021

(C) The Author(s), under exclusive licence to Springer Science+Business Media, LLC, part of Springer Nature 2021

This special issue provides latest research and developments in the area of advances in application of ICT and emerging technologies in industrial engineering and management areas. The special issue present results of research in various aspects of Industry 4.0 paradigm, SMART technologies, intelligent manufacturing systems and applications, Lean management and manufacturing, simulation of manufacturing companies, complexity of supply chain management, management and intelligent infrastructure (road, freight, public transport), RFID in manufacturing, wide range of ICT application challenges, communication ecosystem security, enterprise information system, traffic/ transport / logistic issues in Industry 4.0.

This issue features fourteen selected articles with high quality. The first article, "Determination of contact points between workpiece and fixture elements as a tool for augmented reality in fixture design", considers fork-type parts that have a complex spatial configuration and needs to be machined by drilling-milling-boring equipment in one setup. In fixture design, it is necessary to provide wide tool accessibility, and therefore the choice of locating surfaces of the workpiece is an important step in ensuring the quality of products in manufacturing engineering. The technology of augmented reality is an effective tool at the design stage of fixtures and allows to visualize the developed fixture configurations.

The second article, "Impact of enterprise information systems on selected key performance indicators in construction project management: An empirical study", present results based on a research sample of construction

Lucia Knapcikova

lucia.knapcikova@tuke.sk

Dragan Peraković

dragan.perakovic@fpz.unizg.hr

1 Faculty of Manufacturing Technologies with a Seat in Prešov, Technical University of Košice, Kosice, Slovakia

2 Faculty of Transport and Traffic Sciences, University of Zagreb, Zagreb, Croatia projects in Slovak construction industry. The main objective of the research was set as confirmation of hypotheses, that enterprise information system has an impact on selected key performance indicators like cost and profit.

The third article, "Novel approach for detection of IoT generated DDoS traffic", propose a novel approach for the detection of DDoS traffic generated by IoT devices in a form of a conceptual network anomaly detection model. A proposed conceptual model is based on device classes which are dependent on individual device traffic characteristics. Technological development has resulted in the emergence of the Internet of Things (IoT) concept, whose implementation implies numerous terminal devices with a low level of implemented protection.

The fourth article, "Conceptual model for informing user with the innovative smart wearable device in industry 4.0 “, proposes a conceptual model for informing the people with disabilities regardless of the disability degree using a smart wearable device (smart wristband). All relevant information is integrated through the warehouse management system to efficiently perform all the appropriate processes. The activity of informing users is viewed from multiple scenarios, the work environment and work tasks.

The fifth article, "Advances of intelligent techniques used in Industry 4.0: proposals and testing “, is focused in railway Industry 4.0 concept, on the identification of the most frequently occurring defects in the components of the pressure brakes and the bearing chambers of the wheelset. Research is focused on the identification of the most frequent technical defects in the components of the pressure brakes and the bearing chambers of the wheelset. Using RFID technology it is possible to ensure the monitoring of the technical state of these selected elements.

The sixth article, "Qualitative and quantitative analysis of social network data intended for brand management", presents results of evaluation of the presentation and perception of selected six automotive brands on Twitter and YouTube with the use of qualitative and quantitative analysis tools. The research objects were social networks Twitter and YouTube. 
The seventh article, "AHP method application in selection of appropriate material handling equipment in selected industrial enterprise“, presents an Analytic Hierarchy Process method, used to support decision making on the appropriate handling equipment and specific calculations were carried out in the Expert Choice program.

The eighth article, "Cyber Industry Networks as an environment of the Industry 4.0 implementation ", presents the results of research about the creation of innovative production networks operating in the environment of advanced technologies within Industry 4.0. The aim of the research is to develop the concept of creating temporary Cyber Industry Networks based on e-business platforms that integrate dispersed enterprise resources through mobile devices and mobile software, creating a temporary network in the situation of emerging business opportunities.

The next article, "Integrated process planning and scheduling in networked manufacturing systems for I4.0: a review and framework proposal", presents a literature review carried out about these main subjects. Moreover, a framework for integrated process planning and scheduling in networked manufacturing systems is proposed and briefly described, along with some main underlying issues. The main purpose of this research consists on presenting a proposed methodology, based on the study conducted, to enable to further assist either academia or industry to develop new tools, techniques and approaches for integrated process planning in networked manufacturing environments.

The tenth article, "Energy harvesting cognitive radio networks: security analysis for Nakagami-m fading", offers the precise security capability analysis of EHCRNs under interference power constraint, Nakagami-m fading, maximum transmit power constraint and primary interference. Then, the offered analysis is ratified by computer simulations. Ultimately, multiple results reveal that the security capability is considerably improved with smaller primary interference and lower required security threshold.

In eleventh article, "Secrecy performance analysis of CIOD-OFDM systems over wireless fading channels", the PHY security performance of a combined coordinate interleaved orthogonal design and orthogonal frequencydivision multiplexing (CIOD-OFDM) is evaluated and studied. Closed-form expressions for two performance evaluation metrics of PHY security such as the average secrecy capacity and the secrecy outage probability are derived and presented for the considered CIOD-OFDM system and compared with the secrecy performance of the OSTBC-OFDM system. Mathematical expressions are derived for the general case, where multiple antennas are used at the transmitter and receiver sides. The Monte-Carlo simulation results are also presented for verifying the results obtained from mathematical and theoretical expressions.

The next article, "Importance of organizational structure for TQM success and customer satisfaction", present a structural equation model to relate three critical success factors for total quality management (TQM) (i.e. managerial commitment, the role of the quality department, and quality policies) with customer satisfaction benefits through six hypotheses, which are statistically tested with information from 398 responses to a survey applied to Mexican manufacturing industry and using partial least squares technique integrated in WarpPLS v.6 software. The paper also reports a sensitivity analysis based on conditional probabilities for analyze low and high scenarios.

The thirteenth article, "Performance analysis of bit error rate of data link system under pulse LFM interference in time-varying rayleigh channel", presents a study of the BER performance of the DLS under the pulse linear frequency modulation (LFM) interference in the time-varying Rayleigh channel. In view of the time-varying characteristics of the channel in the practical conditions, the interference channel is modelled as a time-varying Rayleigh fading channel and the formula of BER is derived. Through simulation, the theoretical deduction is proved to be correct.

Last article, "IoT scheduling for higher throughput and lower transmission power", describe an accurate and efficient way confirmed by the simulation to calculate the probability of collision rate and packet loss in LPWANs under various circumstances.

Our sincere thanks to the Editor-in-Chief, Prof. Dr. Imrich Chlamtac and European Alliance for Innovation (EAI) for their continuous support and guidance during the entire process. We also extend our sincere thanks and grateful to the reviewers for their efforts and all suggestion and comments in reviewing tasks of the manuscripts.

Publisher's Note Springer Nature remains neutral with regard to jurisdictional claims in published maps and institutional affiliations. 


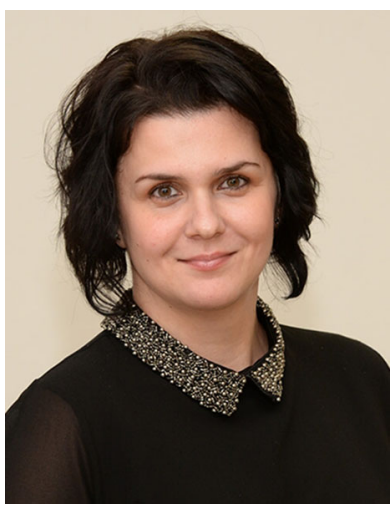

Lucia Knapcikova is Vice-Dean for International Relations and Mobility at the Faculty of Manufacturing Technologies (FMT) of the Technical University of Košice. In 2017 she completed her Habilitation for Associate Professor at the FMT in the field "Manufacturing Technologies". In 2011 she completed her Ph.D. study at the above-mentioned Faculty. Assoc. Prof. Knapčíková, Ph.D., is the author more than 190 scientific papers in Slovakia and abroad and she is the owner of 6 utility models. She participated in several international research projects, mainly in Germany. A most important project is $\mathrm{H} 2020$ Less Than Wagon Load (Project duration 2017-2020) in collaboration with Belgium, Germany, Netherland, Italy and Slovakia, where shés position is the Faculty project coordinator. The project has the objective to develop a SMART specialised logistics cluster for the chemical industry in the Port of Antwerp in order to shift transport volumes from road to rail freight. Actually, she participated in project EUROSTARS (BRIDGE2ERA Program) with the collaboration of Technical University of Applied Sciences in Wildau (TH Wildau), Germany. Aim of the project is Industry 4.0 strategic orientation between universities and SME. She lectured at the universities in Germany (TH Wildau), Czech Republic (TU Liberec) and Croatia (J.J. Strossmayer University of Osijek, Mechanical Engineering Faculty in Slavonski Brod). Her area of interest includes SMART technologies, SMART materials, applications possibilities directly in the industry. In the year 2018, she was awarded in the category "Personality of Science and Technology under 35 years". The Ministry of Education, Science, Research and Sport of the Slovak Republic, in support of the development of science and technology and the recognition of the exceptional achievements in this field, awarded the Science and Technology Awards - the highest award in science and technology, for the year 2018. She is member of European Alliance for Innovation, Belgium (www.eai.eu), TEAM Society in Croatia and an active member of the Editorial Board of Acta Tecnología Journal (Slovakia), SAR Journal (Serbia). She works as Guest Editor in the indexed journal (CC Journal) Wireless Networks-WINET. She is a responsible person for organizing of International conferences under EAI organization- MMS 2021, MMS 2020 and previously MMS2019, MMS2018, MMS2017, MMS2016

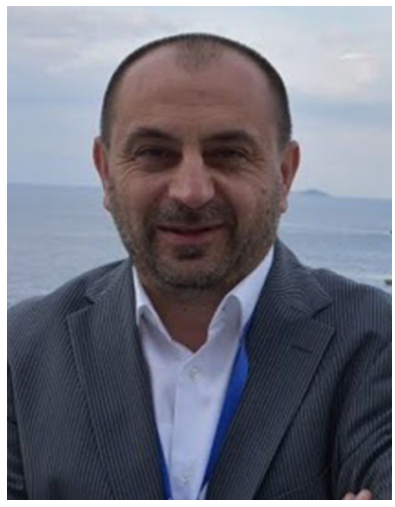

Dragan Peraković received B.Sc. degree in 1995, M.Sc. degree in 2003, and Ph.D. in 2005, all at the University of Zagreb, Croatia, EU. Dragan is Head of the Department for Information and Communication Traffic and Head of Chair of Information Communication Systems and Services Management, all at the Faculty of Transport and Traffic Sciences, University of Zagreb, where he is currently a full professor. Dragan is visiting professor at University of Mostar, Faculty of Science and Education Sciences,
Mostar / Bosnia and Herzegovina. Area of scientific interests and activities is: modelling of innovative communication ecosystems in the environment of the transport system (ITS) and Industry 4.0; AI \& ML in cybersecurity, DDoS, Internet of Things; AI in e-forensic of communication ecosystems (terminal devices / services); design and development of new innovative services and modules. Dragan is an author/co-author of more than 140 scientific papers in indexed journals and proceedings of international conferences and 14 chapters in international scientific books. Additionally, he is co-editor of more than 15 edited indexed books and proceedings. He participated in the work of several international scientific projects and research \& development studies. Dragan is MC member in COST action CA17124 - Digital forensics: evidence analysis via intelligent systems and practices (DigForAsp) \& MC Substitute member in COST action CA15127 - Resilient communication services protecting end-user applications from disaster-based failures (RECODIS). Dragan is a member of TM Forum (USA), IEEE (USA), DAAAM International (EU/Austria), SDIWC (Hong Kong), EAI - European Alliance for Innovation (EU), Association for promotion of innovative technologies InnovativeFET (EU/Croatia), International Association for Technological Development and Innovations (Ukraine), International Telecommunication Society - ITS (EU). Dragan is President of the Croatian Chamber of Transport Engineers, since 2020. Dragan is in top $0.1 \%$ of individuals who achieved the greatest success on the EAI rankings in calendar 2019 among the entire EAI community (EAI Fellows Class 2020). Dragan is the first Chief Editor of the International Journal of Cyber-Security and Digital Forensics (IJCSDF), Hong Kong, and Guest Editor in a few SI in WoS indexed journals. Dragan is a member of the Steering Committee and General Chair at EAI MMS and EAI Fabulous conference series, and a member of big numbers of Program / Scientific / Organization Committee of International Scientific Conference, worldwide. 